appearing before the age of 65 was $65 \%$ in the eastern region and $52 \%$ in the south, compared with $31 \%$ and $5 \%$ respectively in brothers of healthy controls. These results suggest an apparent "ceiling effect," whereby the regional difference in CHD was almost obliterated among those with a positive family history. Conversely, the family history was much more ominous where the background risk was low: in this example the relative risk was about 6 in the south compared with only 1.3 in the high-risk eastern region.

How can we explain familial transmission? The main risk factors certainly run in families, partly through polygenic inheritance (factors such as blood pressure), rarely through the action of a single gene (familial hypercholesterolaemia), and in all cases additionally through a shared environment. Other investigators ${ }^{6}$ have concluded that aggregation of the known risk factors is only an incomplete explanation of the familial clustering of CHD, but the Finnish group disagree. They find very strong clustering of some major risk factors. For hyperlipoproteinaemia (mostly mixed) the relative risk was about 3 and for hypertension about 2, and the authors conclude that these factors accounted for most of the clustering of CHD. The implication is that (in Finland at least) a man with a family history of CHD has no increased risk unless he has a raised blood pressure or serum cholesterol concentration —or (particularly) both.

The extraordinarily high incidence of CHD in eastern Finland has always interested epidemiologists. The Seven Countries Study ${ }^{7}$ showed that it was to be expected from the high levels of risk factors which exist there, particularly the raised serum cholesterol concentrations. This new study extends this conclusion by showing that the big difference in incidence between the east and the south of Finland may again be accounted for by the east having twice the prevalence of hypertension and hyperlipoproteinaemia. We are glad to know that at least in Finland the familial and regional patterns of this disease seem to make sense.

1 Shanoff, H M, et al, Canadian Medical Association fournal, 1961, 84, 519. 2 Rose, G, British fournal of Preventive and Social Medicine, 1964, 18, 75.

3 Slack, J, and Evans, K A, Fournal of Medical Genetics, 1966, 3, 239.

4 Harvald, B, and Hauge, M, Acta Geneticae Medicae et Gemellologiae, $1970,19,248$.

${ }^{5}$ Rissanen, A M, and Nikkila, E A, British Heart fournal, 1977, 39, 875.

${ }^{6}$ Deutscher, S, Ostrander, L D, and Epstein, F H, American fournal of Epidemiology, 1970, 91, 233.

${ }^{7}$ Keys, A, Circulation, 1970, 41-42, suppl 1.

\section{Damaged laryngeal nerves in thyroid surgery}

Damage to the recurrent laryngeal nerve is occasionally an inevitable complication of thyroid surgery. It may be temporary and recover within three months or be permanent. Unilateral paralysis may cause few symptoms, with little alteration in the voice, but bilateral paralysis is a surgical catastrophe. Where the nerve was identified Lahey ${ }^{1}$ found an incidence of $0.3 \%$, but routine postoperative laryngoscopy was not carried out. With identification of the nerve and postoperative laryngoscopy the incidence has been variously reported as $0.6 \%,{ }^{2}$ Till $1.5 \%,{ }^{2}$ Wade $0 \%,{ }^{3}$ and Mountain et al $0 \cdot 27 .{ }^{4}$ When the nerve was not exposed and identified and postoperative laryngoscopy was carried out it rose to $4.5 \%$
(Blomstedt), ${ }^{5} 7 \%$ (Roy), ${ }^{6}$ and $9.5 \%$ in patients having a second operation on the gland (Beahrs). ${ }^{7}$

Most recently $\mathrm{Holt}^{8}$ has examined the problem again and has emphasised the importance of laryngoscopy both before and after operation. In 121 thyroid operations when the recurrent laryngeal nerve was identified either visually or by palpation the incidence of paralysis was $3 \%$, with a further $1 \%$ incidence of injury to the external laryngeal nerve. Preoperative laryngoscopy is essential in all patients but is particularly important in those who have had a previous operation on the gland and in carcinoma of the thyroid. Paralysis of one cord may be seen in patients with benign goitres. ${ }^{9}$ Immediate postoperative laryngoscopy (while the patient is in the operating theatre) is of value if the cords are seen to be moving normally, but pressure by the endotracheal tube or deep anaesthesia may prevent normal movement. Further postoperative laryngoscopy should be carried out within two weeks of the operation; this may identify many cases of unilateral paralysis which would not otherwise have been detected. ${ }^{6}$

Clearly, knowledge of the normal anatomy of the recurrent laryngeal nerve is essential. In a careful study Wade ${ }^{10}$ described eight anatomical variations in 100 thyroidectomies in the relation of the recurrent laryngeal nerve to the inferior thyroid artery: in $46 \%$ of cases the nerve was deep to the arterial trunk or its two divisions; in $10 \%$ it was superficial; while on the right side he identified no fewer than four anomalous nerves. Extralaryngeal branching is not uncommon: in more than one-third of cases the nerve divides into two or more branches. ${ }^{2}$

The nerve may be damaged at the lower pole when it is included in the ligature of the inferior thyroid veins or at the upper pole during haemostasis of the thyroid remnant. In the middle third of its course fixation by the branches of the inferior thyroid artery or enclosure by a nodule places the nerve at risk. Gross displacement of the nerve is common in large retrosternal goitres, when delivery of the gland into the neck will present a risk of damage to the nerve unless all the inferior thyroid veins have been divided first and the retrosternal prolongation of the gland carefully mobilised, when the nerve can then be identified.

The hazard of damage to the nerve can best be avoided by exposing and identifying it. The surgeon may palpate the nerve (it feels like a cord) and identify its position to help in the exposure; he should see it fully and display its relation to the inferior thyroid artery and its branches. This should be sufficient in most cases, but in those in which a previous operation has been carried out or where the surgeon is still in doubt about the nerve's identity a battery-operated stimulator $^{211}$ may be used to check the identity of the exposed nerve at operation. Laryngoscopy will show whether cords are moving or not, but if that is impossible owing to technical problems vibration of the cords may be detected by feeling the exposed thyroid cartilage. ${ }^{12}$.

Injury to the external laryngeal nerve is recognised less commonly. In $15 \%$ of cases Moosman found that the nerve was adherent to the superior thyroid artery and that in $6 \%$ it hooked around the suprapolar branches. ${ }^{13} \mathrm{He}$ suggested that the anterior branch of the superior thyroid artery should be ligated lower down on the upper pole and then the posterior branch tied separately. Holt ${ }^{8}$ also noted the importance of avoiding injury to this nerve, emphasising the disability that results from a combined recurrent laryngeal and external laryngeal nerve paralysis.

Riddell $^{2}$ found 55 cases of a permanent bilateral recurrent 
laryngeal nerve paralysis in a personal appeal to only three laryngologists in Britain, and concluded that many others must have remained undisclosed and undescribed. While the voice may be comparatively unaffected, the airway will always become obstructed. A permanent tracheostomy combined with a Negus speaking valve will provide an adequate airway and a normal speaking voice. Less drastic alternatives include Woodman's operation, ${ }^{14}$ which opens up the cords, providing an airway and eliminating any dyspnoea: the voice will be adequate in three-quarters of cases. ${ }^{15}$ Recently Tucker $^{16}$ has described a method of reinnervating the paralysed cord using a nerve-muscle pedicle; in five patients an adequate airway was obtained with no loss of voice.

1 Lahey, F H, Surgery, Gynecology and Obstetrics, 1944, 78, 239.

2 Riddell, V, British Fournal of Surgery, 1970, 57, 1. Till, A, ibid, p 9.

3 Wade, J S H, Proceedings of the Royal Society of Medicine, 1961, 54, 875.

4 Mountain, J C, Stewart, G R, and Colcock, B P, Surgery, Gynecology and Obstetrics, 1971, 133, 978.

5 Blomstedt, B, Acta Chirurgica Scandinavica, 1959-60, 118, 97.

6 Roy, A D, Gardiner, R H, and Niblock, W M, Lancet, 1956, 1, 988.

7 Beahrs, O H, and Vandertoll, D J, Surgery, Gynecology and Obstetrics, $1963,117,535$.

${ }^{8}$ Holt, G R, McMurry, G T, and Joseph, D J, Surgery, Gynecology and Obstetrics, 1977, 144, 567.

${ }^{9}$ Holl-Allen, R T J, Archives of Otolaryngology, 1967, 85, 335.

10 Wade, J S H, British fournal of Surgery, 1955, 43, 164.

11 Kratz, R C, Laryngoscope, 1973, 83, 59.

12 Rosswick, R P, Lancet, 1973, 1, 772.

${ }^{13}$ Moosman, D A, and DeWeese, M S, Surgery, Gynecology and Obstetrics, 1968, 127, 1011.

14 Woodman, De G, Archives of Otolaryngology, 1946, 43, 63.

15 Woodman, De G, Archives of Otolaryngology, 1953, 58, 150

16 Tucker, H M, Laryngoscope, 1976, 86. 769.

\section{Androgens in the anaemia of chronic renal failure}

We have now stopped searching so hard for methods other than transfusion to raise the haemoglobin concentration in patients with chronic renal failure. This has come about because of the finding that previous blood transfusion aids (probably by inducing immune unresponsiveness) rather than impairs the chances of subsequent survival of renal transplantation. Nevertheless, multiple transfusions in chronic renal failure still have two drawbacks: firstly, there is a risk of introducing hepatitis $B$ (or one of the non-B hepatitis viruses) into a renal dialysis unit; and, secondly, it is never easy to arrange transfusion for patients maintained on a home dialysis programme. Hence research into both the causes and treatment of the anaemia of chronic renal failure continues to be important.

The causes are multiple. Iron deficiency is common, especially in patients on maintenance haemodialysis, in whom excessive small blood losses in sampling and large losses into dialysis machines are important avoidable causes of anaemia. Folic acid is also lost in maintenance dialysis, and replacement of both this and iron is frequently required. The red blood cell membrane shows various transport abnormalities, mainly produced by humoral factors, and, though the decreased survival of red blood cells could be compensated for by a normal bone marrow, in chronic renal failure the marrow turnover is reduced.

Plasma erythropoietin concentrations are reduced or absent in anaemic uraemic patients, owing mainly to the reduction in functional renal mass. ${ }^{1}$ Advanced renal disease also affects the endocrine as well as the secretory function of the kidneys, ${ }^{2}$ and, because plasma erythropoietin concentrations are difficult to measure accurately, we do not know whether there is also some impaired responsiveness to available erythropoietin or whether plasma inhibitors to erythropoietin are present.

Treatment of the anaemia of renal failure should theoretically be aimed at stimulating endogenous production of erythropoietin; increasing marrow responsiveness to it; or identifying and isolating a substance with erythropoietin-like properties. ${ }^{3}$ For years androgens have been known to increase the rate of erythropoiesis; to raise the plasma erythropoietin concentrations of both anaemic and non-anaemic patients with intact kidneys; and to raise the haemoglobin concentrations of patients with chronic renal failure. Their action may mainly depend on increasing erythropoietin production from remnants of the kidneys. Certainly, studies in animals suggest that extrarenal sites of erythropoietin production are relatively unresponsive to the action of androgens ${ }^{4}$ - possibly an important factor in the timing of nephrectomy in patients on dialysis. Moreover, some drugs may also interfere with the action of testosterone. For example, its erythropoietic effect in female rats is almost completely abolished when these are pretreated with phenobarbitone ${ }^{5}-\mathrm{a}$ finding which if confirmed in man would have obvious practical importance.

Androgens have not been effective when used in patients with chronic renal failure not having maintenance dialysis. In those treated in this way, on the other hand, both the haemoglobin concentration and the packed cell volume (PCV) rose. This study was done in men given $300 \mathrm{mg}$ testosterone propionate per week who still retained their kidneys, but no response occurred in anephric patients. ${ }^{6}$ Shaldon et al $^{7}$ reported an improvement in haemoglobin even in anephric patients, but they used a bigger dose of testosterone $(500 \mathrm{mg} /$ week). Synthetic androgens have been used to try to avoid some of the complications of testosterone treatment. Nandrolone decanoate (Decadurabolin), which has to be given intramuscularly, was used in one double-blind trial, and raised both the haemoglobin concentration and the PCV. ${ }^{8}$ Oral synthetic androgens have also been tried. Eschbach and Adamson ${ }^{9}$ used fluoxymesterone with good haematological effect, though with less success in anephric patients; in a controlled trial oxymetholone failed to produce any benefit. ${ }^{10}$ Both these substances are C-17 methylated compounds, and may give rise to reversible liver damage, and will certainly make the patient more sensitive to concomitant warfarin treatment.

The other side effects of long-term androgen therapy may be important. Many men remark on improved sexual performance and increased muscle bulk, but priapism, occurring during sleep during dialysis, seems to be commoner and may result in permanent impotence. Problems in women include hirsutism, coarsening of the features, and acne. Haematomas are common at the injection site, especially since the injection is most conveniently given at the time of heparinisation for dialysis. Azotaemia may also suddenly increase after sudden withdrawal of androgens. ${ }^{11}$

Von Hartitzsch and his colleagues ${ }^{12}$ have recently argued for controlled trials of androgens for the anaemia of renal failure. In the meantime they suggest that androgens should be prescribed selectively for anaemic men on regular haemodialysis-a reasonable summary of the small place of these drugs in chronic renal failure.

\footnotetext{
1 Lancet, 1975, 1, 959.

2 DeGowin, R L, et al, Annals of Internal Medicine, 1970, 72, 913.

3 Naets, J P, Nephron, 1975, 14, 181.

4 Wang, F, and Fried, W, Fournal of Laboratory and Clinical Medicine, $1972,79,181$.
} 